\title{
The Implementation of Dual Pathway Creativity Model on Tourism Sector in West Sumatra
}

\author{
Mega Asri Zona ${ }^{\mathrm{a}, *}$, Arif Adrian ${ }^{\mathrm{b}}$ \\ ${ }^{a}$ Faculty of Economics, Universitas Negeri Padang \\ ${ }^{b}$ Faculty of Tourism and Hospitality, Universitas Negeri Padang
}

\begin{abstract}
This research examined the implementation of the Dual Pathway Creativity Model (DPCM) as a function of cognitive flexibility and cognitive persistence in employees working at companies engaged in the tourism sector in West Sumatra. Dual Pathway Creativity Model (DPCM) suggests a more comprehensive theory about employee creativity. DPCM argues that a flexible and pleasant environment can encourage flexibility and creativity. However, problems and a less flexible environment might also encourage creativity, but through a different process compared to a flexible environment. This research used a purposive sampling technique with 96 respondents, consisting of employees working in the tourism sector. The results showed that cognitive flexibility had a positive effect on employee creativity in the tourism sector in West Sumatra, while cognitive persistence had a negative effect on employee creativity in the tourism sector in West Sumatra.
\end{abstract}

\section{Keywords:}

creativity, cognitive flexibility, cognitive persistence, dual pathway creativity model (DPCM), tourism

\section{INTRODUCTION}

Indonesia is implementing massive changes towards the industrial revolution 4.0. These changes require some expertise, including complex problem solving, critical thinking, people management, negotiation, and creativity. Creativity is an exciting topic because creativity is initially positioned as an inherent skill in a person. However, research has found that the environment can influence creativity from the outside. This research wants to see what can be done by organizations to foster the creativity of their employees.

Creativity is generally defined as the production of ideas, problem-solving, and products that have original and appropriate properties (feasible, possibly useful) (Amabile, 1983). Originality is considered a sign of creativity and that a person cannot be creative without being original. However, original or inappropriate ideas or products will be considered unreasonable and irrelevant.

Employee creativity is an exciting research topic in the field of Human Resource Management (HRM) in recent years. However, the theoretical development is lagging (Nijstad et al., 2010).

\footnotetext{
*Author in correspondence,

Email address: megaasrizona@fe.unp.ac.id (Mega Asri Zona)
}

ISSN: 2549-3221 (Print) 2549-323X (Online)

DOI: 10.26487 /hebr.v3i2.1993
Creativity means realizing, investing in new forms, producing something through imaginative skills (Nijstad et al., 2010). Another definition states that creativity is the ability to make or present something new, including new solutions to problems, new methods or devices, or new objects or artistic forms. These definitions highlight two main determinants of creativity. First, there must be something new, imaginative, different, or unique this component is generally referred to as 'difference.' Second, the different things that are produced must solve the problem or have some 'relevance.'

An organization needs to adapt to changing environments through innovation that result from employee creativity to survive. Humans, in general, are creative creatures. However, the level of creativity varies and is influenced by many factors ( $\mathrm{Ni}$ jstad et al., 2010).

Dual Pathway Creativity Model (DPCM) suggests that creativity can not only be created through a flexible environment but also can be in environments with high persistence. This research is essential because not all organizations in the Indonesian tourism sector can create a flexible environment for their employees, and not all of the employee creativity resulted from the flexible environment while the organization requires creative ideas to create innovation. Compared to flexible thinking, the problem creates a way that makes the mind more focused, which is likely through persistence is also positively related to employee creativity. Although this model has received support 
through experiments, this model has never been tested through research in the field.

Creativity is the creation of ideas that are useful and have a novelty value by an individual or a small group consisting of individuals who work together (Amabile and Pratt, 2016), while innovation is a success in applying the creative ideas in an organization. Research by Nijstad et al., 2010 suggested that social-psychological factors influence a person's creative performance. Positive and negative social factors affect a person's creative performance. The creative performance focuses on novelty, is rarely available statistically, is unique in its entirety, is appropriate in solving problems, is effective, and has surprises.

Previous research assumes that creativity will develop in a flexible environment. However, some researchers have argued that creativity can arise in inflexible environments. This research wants to test the performance of other types of employee creativity as a function of cognitive flexibility and persistence (Nijstad et al., 2010).

The most important contribution of DPCM to the creativity model is that it suggests that some personalities and conditions affect cognitive flexibility while others affect cognitive persistence. The expected creativity in this research is creativity, which will produce an innovation. This research will look at creativity in organizations engaged in the tourism sector.

The tourism sector is one of the industries that are the mainstay of government revenue. This sector continues to show an increase in income every year. The growth of Indonesia's tourism sector in recent years has reached $25.68 \%$. Tourism is the second largest contributor to Indonesia's foreign exchange in 2017. Besides, compared to neighboring countries such as Malaysia, Singapore, and Thailand, Indonesia is also superior in terms of tourism branding and destinations with various awards won by Indonesia. Indonesia's Tourism Competitiveness Index, according to the World Economy Forum, shows encouraging developments. Indonesia's ranking rose 8 points from 50 in 2015 , to rank 42 in 2017. One thing from the increase in the number of foreign tourists who during the last three years from 10 million people in 2015 to 12 million last year increased the country's foreign exchange income from the US $\$ 12.336$ billion to the US $\$ 12.44$ billion.

The tourism sector needs creative human resources to attract tourists. However, not all companies involved in this sector can create a flexible environment to encourage the creativity of their employees. Therefore, the authors are interested in researching the implementation of the Dual Pathway Creativity Model (DPCM) in the tourism sector of West Sumatra, Indonesia.

\section{LITERATURE REVIEW}

Creativity theory states that a comprehensive model of social and psychological components is needed for an individual to produce creative work. This theory is based on the definition of creativity as the production of new ideas or results that are suitable for several purposes (Amabile, 2012). Four components are needed for each creative response: three components in an individual: skills that are relevant to the domain, processes that are relevant to creativity, and intrinsic motivation; and one component outside the individual, namely the social environment in which the individual works. The latest version of this theory includes organizational creativity and innovation, bringing implications for the work environment created by managers. This version defines the components of creativity and how they influence the creative process, describing modifications to the theory over time. Then, after comparing component theory with other theories of creativity, the article explains the evolution and impact of the theory.

Although humans are creative creatures, the level of creativity varies between individuals (trait-based variation) and between different situations (state-based variation) (Nijstad et al., 2010). For example, social psychology research shows that a person's creative performance is influenced by a variety of dispositions and situations that cause certain moods, by external evaluation and reward. This research looks at state-based variation and state-based variation in influencing creativity.

DPCM proposed by De Dreu et al., 2008 will be the basis for testing the influence of the environment on the creation of employee creativity. DPCM assumes that there are two ways to create creative performance, through flexibility and persistence, and psychological conditions affect creativity through their impact on both paths. DPCM is built on previous theories about creativity. This model was initially developed by De Dreu et al. (2008) to see the influence of positive and negative moods on creative performance. This model was then redeveloped after previous research found that systematic and focused thinking could and could produce high levels of creativity with several circumstances (Rietzschel et al., 2007). This research breaks the assumption that focused, systematic, and analytical thinking is not in line with creativity.

DPCM adds the previous theory of creativity in two ways. First, as indicated in its name, this theory assumes two different processes that are likely to produce creativity: flexibility pathway and persistence pathway. Second, this model is a socio-psychological model, which assumes that different circumstances and personalities are associated with creativity because it affects cognitive flexibility, or influences cognitive persistence or both.

The tourism sector needs creative human resources to attract tourists. However, not all companies involved in this sector can create a flexible environment to encourage the creativity of their employees. Therefore, the authors are interested in researching the Implementation of Dual Pathway Creativity Model (DPCM) in the Indonesian Tourism Sector. Previous research on creativity suggests that creativity will only develop in a flexible environment. However, some researchers argue that creativity can emerge in an inflexible environment. Dual Pathway Creativity Model (DPCM) presents a more comprehensive theory of employee creativity.

Flexibility pathways represent the possibility of creating insight, problem-solving, and creative ideas through the use of broad and inclusive cognitive categories, through flexible transitions between categories, approaches, and sets, and the use of remote associations (Amabile, 1983). Creativity is often as- 
sociated with making new connections between general ideas. Creative individuals do not rely on ordinary thinking and use regular strategies, but have a broad focus of attention and flexibly switch between approaches to tasks.

As explained earlier, several researchers associate cognitive flexibility with the availability of dopamine in specific brain areas and with a decrease in the level of inherent resistance. However, the disadvantage of increasing flexibility is that it will be associated with reduced cognitive control and increased distractibility, when the threshold for ideas to enter working memory is lower; it is unavoidable that irrelevant thoughts or solutions the bad ones are also considered. Therefore, evaluation mechanisms are needed to assess the suitability of responses, and cognitive processes need to be adjusted when obtaining flexible pathways, which require at least some control mechanisms that keep our behavior in line with our goals and our internal intentions. Assuming that cognitive control is associated with general mental abilities, for example, working memory capacity, this is in line with evidence that shows that the level of inherent resistance is only related to creativity for people with high mental.

Persistence pathway represents the possibility of achieving creative ideas, insights, and solutions to problems through hard work, systematic and effective exploration of possibilities, and in-depth exploration in only a few categories or perspectives. Indeed, some authors argue that creativity can be achieved through a systematic exploration of the problem space and additional search processes (Nijstad et al., 2010). Systematic thinking and additional search are usually not related to creativity because these processes will initially lead to clear and available solutions. On the contrary, the systematic search will only produce original ideas, insights, and solutions after more easily available ideas have been examined and discarded to arrive at an initial response because it requires persistence.

The systematic search process used in the persistence path requires more executive control than the associative search process used in the flexibility path. Systematic thinking requires that distracting and irrelevant thoughts are blocked from working memory, and attention is entirely focused on the task at hand. It may imply that more distant colleagues are not ready to be considered because they are filtered before they reach the activation threshold needed to enter working memory. Thus, when the persistence path is used, people will become less easily distracted, but also generally less flexible.

Flexibility and systematic cognitive search processes are negatively related. In cognitive psychology, this has been described as an exchange between flexibility and stability. One function of attention is to stay focused on the task (such as keeping one goal active in working memory) and ignoring interference; this is achieved through the inhibition of irrelevant material. However, while the inhibition of ideas that seem irrelevant will lead to stability in terms of the pursuit of goals, it will also reduce the breadth of the focus of attention and thus prevent ideas that are further from entering working memory, which can jeopardize cognitive flexibility. Some authors attribute flexibility-stability to trade with the dopaminergic system and argue that the dopamine balance in different areas of the brain (frontal) determines whether processing modes are flexible or systematic.

The exchange between flexibility and stability can lead to the hypothesis that the path of flexibility and persistence is negatively related. However, this does not need to happen because people can switch from more flexible to systematic processing modes (Nijstad et al., 2010). In the process of problem solving or creative ideation, people can use a flexible and systematic processing mode, although it may be at different levels. For example, a person might use a path of flexibility to find new and promising approaches to a task and then moves on to a more systematic approach to further exploring this approach. Thus, over time, the use of flexibility paths does not exclude the use of persistence paths or vice versa. The research model explained in Figure 1.

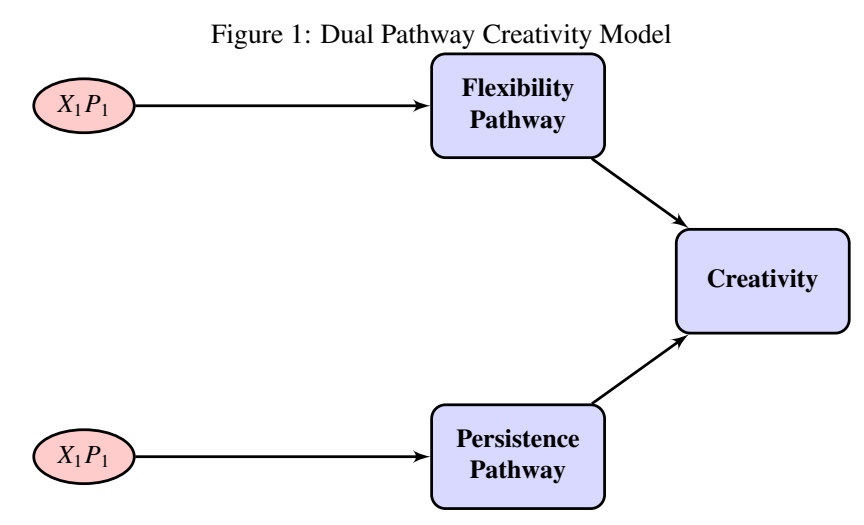

\section{METHODS}

This research is quantitative research with cross-sectional data collection method, research by gathering data in one time to answer questions. In this research, the sampling technique that will be used is purposive sampling technique, with the specified criteria, namely employees who work in companies engaged in the tourism sector in West Sumatra. This research will focus on the hospitality industry. It is because the hospitality industry has a significant role in the tourism industry. Besides, the hotel industry also has a large number of employees compared to other industries in the tourism sector. The total respondents targeted in this research were 96 respondents.

Data collection techniques in this research using a survey by distributing questionnaires to the predetermined respondents. Data analysis methods include testing research instruments and testing hypotheses. To test the hypothesis, the data obtained from the results of this research will be analyzed using multiple regression analysis. Multiple regression analysis is performed to examine the simultaneous impact of the independent variables on the dependent variable.

\section{ANALYSIS}

\section{Analysis}

This research aims to look at the effect of flexibility pathway and persistence pathway on employee creativity in the tourism 
sector in West Sumatra. Each of the research variables can be described as follows.

Table 1: Mean of Variables

\begin{tabular}{|c|c|c|c|c|}
\hline Variable & $\begin{array}{l}\text { Total } \\
\text { Score }\end{array}$ & Mean & Percentage & $\begin{array}{l}\text { Expla- } \\
\text { nation }\end{array}$ \\
\hline $\begin{array}{l}\text { Flexibility } \\
\text { pathway }\end{array}$ & 4940 & 3,8 & 76 & Good \\
\hline $\begin{array}{l}\text { Persistence } \\
\text { pathway }\end{array}$ & 3387 & 3,76 & 75,26 & Good \\
\hline Creativity & 2979 & 3,72 & 74,47 & Good \\
\hline Average & 3768,7 & 3,76 & 75,2 & Good \\
\hline
\end{tabular}

Based on the table above, it can be seen that the average of the three variables is 3.76 or $75.2 \%$. It means that the respondent's achievement of the suitability of the statements is excellent or appropriate because it meets the classification criteria of the average response of respondents with a value of $61-80 \%$. It shows that the level of flexibility pathway, persistence pathway, and creativity are right. From the statements listed, the flexibility pathway variable obtained the highest score of 3.80 or $76 \%$.

The questionnaire consists of two parts; (1) contains questions regarding the demographic characteristics of respondents, including educational background, (2) contains statements about employee creativity variables, cognitive flexibility, and cognitive persistence. The first part questionnaires are demographics and educational background, each categorical. The second part of the questionnaire was a statement about the variables to be examined on a scale of 1 to $5(1=$ strongly disagree $-5=$ strongly agree). The questionnaire in this research will be given in person (self-administrated survey). Using questionnaires to find out the opinions of respondents related to research conducted to identify the properties and conditions associated with cognitive flexibility, cognitive persistence, or both of which affect creativity in employees who work in the tourism sector in West Sumatra.

This research analyzes the effect of two independent variables flexibility pathway $\left(X_{1}\right)$ and persistence pathway $\left(X_{2}\right)$ that affect creativity $(Y)$. Analysis of using multiple regressions with the results of the analysis can be seen in the Table 2 .

The equation obtained is

$$
Y_{i}=4.072+0.573 X_{1 i}-0,204 X_{2 i}+\epsilon_{i}
$$

Based on the regression equation above, it can be interpreted as follows: A constant of 4,072 shows that without the independent variables namely flexibility pathway $\left(X_{1}\right)$ and persistence pathway $\left(X_{2}\right)$, there will be a decrease in creativity $(\mathrm{Y})$ of 4,072 . The value of the regression coefficient $(\beta)$ of the flexibility pathway $\left(X_{1}\right)$ obtained is positive, which is 0.573 , indicating that every increase in the flexibility pathway variable is one unit, there will be an increase in creativity by 0.573 . It shows that if the flexibility pathway increases, the creativity of employees working in the West Sumatra tourism sector will also increase.
The value of the regression coefficient $(\beta)$ of the pathway persistence variable $\left(X_{2}\right)$ obtained the negative value of -0.204 indicates that each increase in the persistence pathway variable one unit, there will be a decrease in the creativity of employees working in the tourism sector of West Sumatra by -0.204 units. It shows that if the pathway persistence increases, the creativity of employees working in the tourism sector in West Sumatra will decrease.

To examine the proposed hypothesis, this research testing the hypothesis through the t-test. T-test was conducted to see the partial effect of each independent variable on the dependent variable. Based on the analysis results in Table 2, the following results are obtained.

\section{Hypothesis 1}

The flexibility pathway significantly influences the creativity of employees who work in the tourism sector in West Sumatra. Based on Table 2, note that the value of Sig. $0.00 ; 0.05$, which means that the flexibility pathway $\left(X_{1}\right)$ has a positive and significant effect on the creativity of employees working in the tourism sector in West Sumatra. Thus Ho is rejected, and Ha is accepted. It means that the higher the flexibility of the pathway, the higher the creativity of West Sumatra tourism sector employees.

\section{Hypothesis 2}

The persistence pathway based on Table 2 notes that the value of Sig. $0.025 ; 0.05$, which means that the persistence pathway has a negative and significant effect on the creativity of the employees of the tourism sector in West Sumatra (Y). Thus Ho is rejected, and Ha is accepted. It means that if the pathway persistence increases, creativity will decrease.

The determination coefficient indicates the magnitude of the proportion of the contribution of the independent variable to the dependent variable. From Table 2, it can be seen that adjusted $\mathrm{R}$-square 0.677 means that the contribution of variable flexibility pathway and persistence pathway to employee creativity in the West Sumatra tourism sector is $67.7 \%$, while $32.3 \%$ is determined by other factors not included in this research.

\section{Discussion}

Based on the results of data analysis and hypothesis testing, it can be put forward a discussion aimed at explaining and interpreting the results of research:

\section{Hypothesis 1}

Based on the analysis of the frequency distribution of cognitive flexibility, variables in Table 1 with the level of achievement of respondents with an average of 3.80 or $76 \%$. It states that cognitive flexibility is in the first category; it means that the employee's cognitive sensitivity in working towards creativity is good.

From the results of multiple regression analysis, it is known that cognitive flexibility significantly influences the creativity of employees working in the tourism sector in West Sumatra. It can be seen from the Sig. $0.00 ; 0.05$, and this can be interpreted if cognitive flexibility is increased, the creativity of 
Table 2: Results

\begin{tabular}{llllll}
\hline \multirow{2}{*}{ Model } & \multicolumn{2}{l}{ Unstandardized Coefficients } & $\begin{array}{l}\text { Standardized } \\
\text { Coefficients }\end{array}$ & \multirow{2}{*}{ S } & \multirow{2}{*}{ Sig } \\
\cline { 2 - 4 } & $\mathrm{B}$ & Std.Error & Beta & \\
\hline (Constant) & 4.072 & 1.946 & & 2.092 & .039 \\
Fexiblity Pathway & .573 & .053 & .971 & 10.850 & .000 \\
Persistence Pathway & -.204 & .090 & -.204 & -2.276 & .025 \\
Dependent Variable: Creativity & & & & \\
\hline
\end{tabular}

employees working in the tourism sector in West Sumatra will also increase.

The disadvantage of increasing flexibility is that it will be associated with reduced cognitive control and increased distractibility (Dreisbach and Goschke, 2004). Therefore, evaluation mechanisms are needed to assess the appropriateness of the responses generated (Dietrich, 2004), and cognitive processes need to be adjusted when getting a flexible path, which requires at least some control mechanism that keeps employee behavior in line with goals and our internal intentions (cognitive control (Nijstad and Stroebe, 2006)).

\section{Hypothesis 2}

Based on the results of the analysis of the frequency distribution of cognitive persistence, variables can be seen in Table 1 1 with the level of achievement of respondents with an average of 3.76 or $75.26 \%$. It states that cognitive persistence is in the first category. From the results of multiple regression analysis, it is known that cognitive flexibility significantly influences the creativity of employees working in the tourism sector in West Sumatra. It can be seen from the value of Sig. $0.00 ; 0.25$, and this can be interpreted if the cognitive sensitivity is improved, the creativity of employees working in the tourism sector in West Sumatra will decrease. It shows that DPCM cannot be implemented thoroughly in the respondents of this research. It is because creativity will only be high if the employee is in a flexible environment. However, in environments with high persistence, creativity will decrease.

Several factors can cause a persistence pathway to have a negative and significant effect on creativity. According to Amabile (2012), one of the factors that influence is employee personality. Employees with judging and sensing personalities will prefer order, control, and regulation, so working in an environment of high persistence will increase their creativity. However, employees who have intuitive and flexible personalities will find it challenging to be creative in environments with high persistence.

\section{CONCLUSION}

This research wants to see the implementation of the dual pathway creativity model (DPCM) as a function of cognitive flexibility and cognitive persistence in employees working in companies engaged in the tourism sector in West Sumatra. Dual Pathway Creativity Model (DPCM) suggests a more comprehensive theory about employee creativity. DPCM argues that a flexible and pleasant environment can encourage mind flexibility and creativity.

However, problems and a less flexible environment might also encourage creativity, but through a different process with a more flexible environment. This research used a purposive sampling technique with 96 respondents, consisting of employees working in the tourism sector. The results showed that cognitive flexibility had a positive and significant effect on employee creativity in the tourism sector in West Sumatra, while cognitive persistence had a negative and significant effect on employee creativity in the tourism sector in West Sumatra.

\section{References}

Amabile, T. M. (1983). "The Social Psychology of Creativity: A Componential Conceptualization". In: Journal of Personality and Social Psychology 45, pp. 357-376.

- (2012). "Componential Theory of Creativity". Harvard Business School, Working Paper.

Amabile, T. M. and M. G. Pratt (2016). "The Dynamic Componential Model of Creativity and Innovation in Organizations: Making Progress, Making Meaning". In: Research in Organizational Behavior 36, pp. 157-183.

De Dreu, C. K. W., M. Baas, and B. A. Nijstad (2008). "Hedonic tone and activation in the mood-creativity link: Towards a dual pathway to creativity model". In: Journal of Personality and Social Psychology 94, pp. 739-756.

Dietrich, A. (2004). "The Cognitive Neuroscience of Creativity". In: Psychonomic Bulletin Review 11, pp. 1011-1026.

Dreisbach, G. and T. Goschke (2004). "How Positive Affect Modulates Cognitive Control: Reduced Perseveration at The Cost of Increased Distractibility". In: Journal of Experimental Psychology: Learning, Memory, and Cognition 30, pp. 343-353.

Nijstad, B. A., C. K. W. De Dreu, E. F. Rietzschel, and M. Baas (2010). "The Dual Pathway to Creativity Model: Creative Ideation as a Function of Flexibility and Persistence". In: European Review of Social Psychology 21, pp. 34-77.

Nijstad, B. A. and W. Stroebe (2006). "How The Group Affects The Mind: A Cognitive Model of Idea Generation in Groups". In: Personality and Social Psychology Review 10, pp. 186-213.

Rietzschel, E. F., C. K. W. De Dreu, and B. A. Nijstad (2007). "Personal Need for Structure and Creative Performance: The Moderating Influence of Fear of Invalidity". In: Personality and Social Psychology Bulletin 33, pp. 855866. 